\title{
Correction of Double-Chambered Right Ventricle 40 Years after Pulmonary Valvuloplasty
}

\author{
Elmar W. Kuhn ${ }^{1}$ Gerardus Bennink ${ }^{1}$ Thorsten Wahlers ${ }^{1}$ Jens Wippermann ${ }^{1}$ \\ ${ }^{1}$ Department of Cardiothoracic Surgery, Heart Center Cologne, \\ Cologne, Germany \\ Thorac Cardiovasc Surg Rep 2015;4:31-33. \\ Address for correspondence Elmar W. Kuhn, MD, Department of \\ Cardiothoracic Surgery, Heart Center Cologne, Kerpener Str. 62 \\ 50937, Cologne, Cologne 50937, Germany \\ (e-mail: elmar.kuhn@uk-koeln.de).
}

\begin{abstract}
Keywords

- congenital heart disease

- heart valve disease

- pulmonary valve also be diagnosed in young adults.

\section{Introduction}

Double-chambered right ventricle (DCRV) is a rare anomaly with tissue dividing the right ventricle (RV). The division can be caused by hypertrophied or anomalous muscle or aberrant moderator band, resulting in intraventricular pressure gradients. Many congenital heart defects can be associated with DCRV such as ventricular septal defect, tetralogy of Fallot, or Ebstein anomaly. ${ }^{1}$ We describe a patient who presented with DCRV 40 years after surgical pulmonary valvuloplasty.
\end{abstract}

Background Double-chambered right ventricle is a partial separation of the right ventricle by pathological tissue. This anomaly is described in infants and children but can

Case Description A 47-year-old patient presented with chest pain and exercise intolerance. Further evaluation revealed a double-chambered right ventricle. During the surgical procedure, fibrotic tissue was transected, and a pulmonary valve replacement including enlargement of the main pulmonary artery was performed.

Conclusion Subpulmonary obstruction of the right ventricle can be related to doublechambered right ventricle even in adulthood. Treatment options include surgical resection with pulmonary valve replacement.

\section{Case Description}

A 47-year-old woman (size $158 \mathrm{~cm}$; weight $68 \mathrm{~kg}$ ) with a history of surgical pulmonary valvuloplasty 40 years ago in Turkey was admitted with progressive chest pain and exercise intolerance. Documentation of the initial procedure was scarce; therefore, no further information about the former presence of a ventricular septal defect (VSD) was provided. Coronary artery disease was excluded. Recurrent pulmonary stenosis plus an additional subvalvular obstruction of the RV was revealed by echocardiography. Maximal gradients through the intraventricular stenosis and the pulmonary valve were 77 and $84 \mathrm{~mm} \mathrm{Hg}$, respectively, with a maximal
Doppler flow velocity of $4.6 \mathrm{~m} / \mathrm{s}$. Pulmonary valve diameter was $20 \mathrm{~mm}$ evaluated by echocardiography, resulting in a z-score of -2 (adjusted for sex and body surface area) with a diameter of the aortic valve of $22 \mathrm{~mm}$. Right heart catheterization showed suprasystemic RV pressure of $163 / 5 \mathrm{~mm} \mathrm{Hg}$. Subvalvular pulmonary stenosis was confirmed by angiography and magnetic resonance imaging (MRI).

For the operative procedure, cardiopulmonary bypass was instituted via peripheral vessels. An additional venous cannula was inserted via the superior vena cava for unloading of the RV. After administration of cardioplegia, the infundibulum of the RV was opened in cardiac arrest revealing two bulging muscle rings covered with scar tissue obstructing the subvalvular outflow tract. The fibrous scar was removed and the hypertrophied moderator band was transected. Inspection of the pulmonary valve showed a continuation of the fibrous tissue into the valvular apparatus with thickening and fusion of the leaflets without possibility for a reconstructive approach. The incision was therefore extended across the annulus of the pulmonary valve into the main pulmonary artery. The thickened leaflets of the valve were removed in total and a Carpentier-Edwards PERIMOUNT (Edwards Lifesciences, Irvine, California, United States) aortic pericardial bioprosthesis (23 mm, model 2900) was inserted using received

February 13, 2015 accepted after revision April 21, 2015

published online

July 15, 2015
Dol http://dx.doi.org/ $10.1055 / \mathrm{s}-0035-1556814$. ISSN 2194-7635. (c) 2015 Georg Thieme Verlag KG
Stuttgart . New York

License terms

(요 (1) $\Theta$ 
Teflon-reinforced U-stitches with the pulmonary annulus covering about two-thirds of the prosthesis (-Fig. 1). An Auto Tissue Matrix Patch (Auto Tissue $\mathrm{GmbH}$, Berlin, Germany) was then used for enlargement of the main pulmonary artery and for covering the remaining one-third of the prosthesis and the RV (-Fig. 2). The patient was then weaned from cardiopulmonary bypass.

The following clinical course was uneventful. The patient was extubated within 9 hours and transported to the normal ward after 4 days. Routine echocardiographic follow-up revealed a no gradient across the prosthesis and no valvular regurgitation with a maximal pressure gradient of $12 \mathrm{~mm} \mathrm{Hg}$ and a Doppler velocity of $170 \mathrm{~cm} / \mathrm{s}$.

\section{Discussion}

The patient was operated for DCRV 40 years after surgical pulmonary valvuloplasty. Because DCRV is typically considered to be a congenital heart disorder, this might have been misdiagnosed in childhood or become more prominent in the following decades as investigated by Oliver et al in a series of patients showing a fast progression of midventricular obstruction in adolescents and young adults with DCRV. ${ }^{2}$ As exact information about the initial procedure performed in Turkey 1974 was not available, the former presence of a VSD was unknown at the time of admission. However, there was no intraoperative evidence about a past surgical VSD closure.

In the presented case, the sequence of diagnostic investigations was a transthoracic followed by transesophageal echocardiography, right and left heart angiography, and finally magnetic resonance imaging (MRI), as MRI is considered the best imaging modality. ${ }^{3}$ Excellent functional and hemodynamic results have been reported after surgical correction. ${ }^{4}$ Reconstruction of the pulmonary valve including the right ventricular outflow tract (RVOT) was considered in this case as previously described. ${ }^{5}$ However, reconstruction seemed to provide a questionable approach because of the massive thickening and fusion of the leaflets. A development of a significant restenosis in this specific patient is presumed

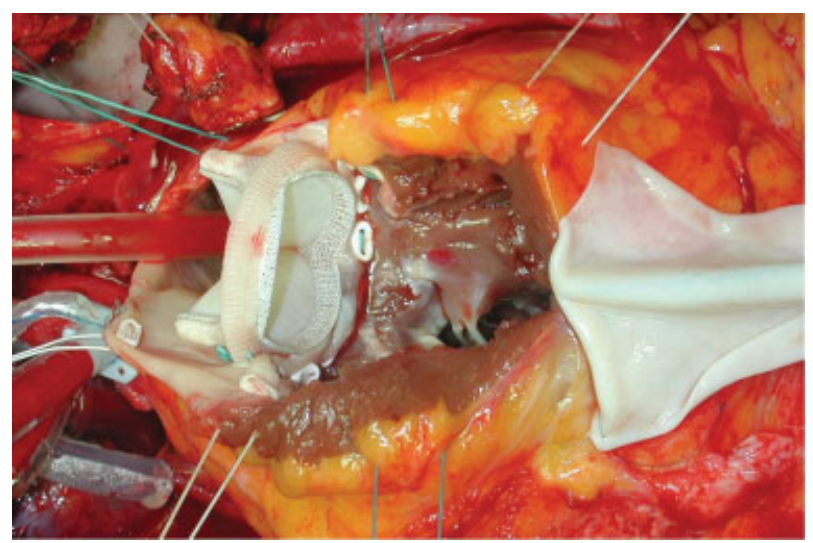

Fig. 1 Surgical view on the right ventricular outflow tract with incision of the right ventricle across the annulus of the pulmonary valve into the main pulmonary artery. The bioprosthesis is inserted with the pulmonary annulus covering about two-thirds the prosthesis. The patch is attached to the ventricular end of the incision.

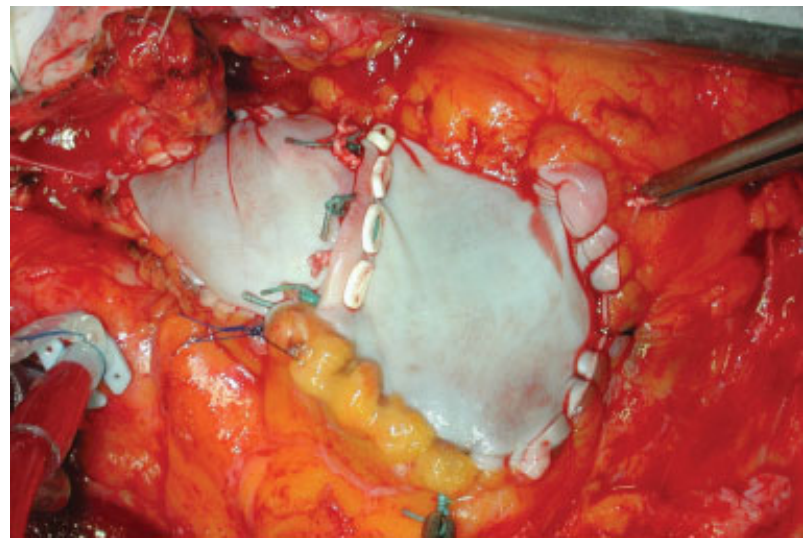

Fig. 2 Surgical view on the right ventricular outflow. The patch covers the ventricular incision and about one-third of the bioprosthesis simultaneously enlarging the main pulmonary artery.

to be unlikely, as the pressure gradient was dramatically reduced when compared with preoperative values. However, this needs to be verified in the future by follow-up echos.

The cardiopulmonary bypass was instituted via peripheral vessels as a standard approach for redo-cases at our institution. After connection to the cardiopulmonary bypass, the chest was opened and the heart freed from adhesions. Beside the chosen stented bioprosthesis, there would have been other options for pulmonary valve replacement. However, especially the stented valves offer the option for future transcatheter pulmonary valve implantation (e.g., Melody valve, Medtronic, Inc., Minneapolis, Minnesota, United States) in case of recurrent pulmonary valve stenosis. In the presented case, the initial plan was a reconstruction of the pulmonary valve and not a valve replacement; therefore, a pulmonary homograft was not available at the time of operation. Pulmonary valve replacements with the Carpentier-Edwards PERIMOUNT prosthesis have been described with good clinical long-term outcomes. ${ }^{6}$ When compared with the investigation of Neukamm et al, the size of the implanted valve ( $23 \mathrm{~mm}$ ) was relatively small; however, the RVOT was needed to be enlarged with a patch to realize the implantation of this valve. In general, the aim was to implant a valve that is as large as possible with a change of z-scores from -2 (preoperatively) to -0.5 (postoperatively).

\section{References}

1 Loukas M, Housman B, Blaak C, Kralovic S, Tubbs RS, Anderson RH. Double-chambered right ventricle: a review. Cardiovasc Pathol 2013;22(6):417-423

2 Oliver JM, Garrido A, González A, et al. Rapid progression of midventricular obstruction in adults with double-chambered right ventricle. J Thorac Cardiovasc Surg 2003;126(3):711-717

3 Ibrahim T, Dennig K, Schwaiger M, Schömig A. Images in cardiovascular medicine. Assessment of double chamber right ventricle by magnetic resonance imaging. Circulation 2002;105(22): 2692-2693

4 Said SM, Burkhart HM, Dearani JA, O'Leary PW, Ammash NM, Schaff HV. Outcomes of surgical repair of double-chambered right ventricle. Ann Thorac Surg 2012;93(1):197-200 
5 Hiramatsu Y. Pulmonary cusp and annular extension technique for reconstruction of right ventricular outflow in tetralogy of Fallot. Ann Thorac Surg 2014;98(5):1850-1852
6 Neukamm C, Lindberg HL, Try K, Døhlen G, Norgård G. Pulmonary valve replacement with a bovine pericardial valve: a five year followup study. World J Pediatr Congenit Heart Surg 2014;5(4):534-540 